\title{
Detection of Cancer Biomarkers with Nanotechnology
}

\author{
${ }^{1,2}$ Lei Zhang, ${ }^{1,3}$ Dan Lv, ${ }^{1}$ Weijun Su, \\ ${ }^{1}$ Yanhua Liu, ${ }^{1}$ Yanan Chen and ${ }^{1}$ Rong Xiang \\ ${ }^{1}$ Department of Immunology, School of Medicine, Nankai University, Tianjin 300071, P. R. China \\ ${ }^{2}$ Institute of Modern Optics, Nankai University, Tianjin 300071, P. R. China \\ ${ }^{3}$ Moores Cancer Center, University of California, San Diego, CA 92093, U.S.A
}

Received 2012-10-31, Revised 2013-02-16; Accepted 2013-03-07

\begin{abstract}
Early detection of cancer biomarkers with high precision is critically important for cancer therapy. A variety of sensors based on different nanostructured materials have attracted intensive research interest due to their potential for highly sensitive and selective detection of cancer biomarkers. This review covers the use of a variety of nanostructured materials, including carbon nanotubes, silicon nanowires, gold nanoparticles and quantum dots, in the fabrication of sensors. Emphases are placed on how the detection systems work and what detection limits can be achieved. Some assays described in this review outperform established methods for cancer biomarker detection. It is highly promising that these sensors would soon move into commercial-scale production and find routine use in hospitals.
\end{abstract}

Keywords: Cancer, Biomarker, Nanostructured Materials, Sensor, Immunoassay

\section{INTRODUCTION}

Cancer is a highly heterogeneous and adaptable disease that is known for its high mortality rates and the recurrence after treatment (Craene and Berx, 2013). According to the 2012 Report to the Nation on the status of cancer, approximately $2 \%$ of the total U.S. population dies with cancer each year (Eheman et al., 2012). Cancer poses an even more serious threat in the fast developing countries. It is now the leading cause of death in urban China (Zhao et al., 2010).

Early detection of cancer is one of the most hopeful approaches to reduce cancer death rates. Table 1 shows the survival rates for people with lung, colorectal, breast and prostate cancers diagnosed at the late stage (i.e., cancer with metastasis to distant tissues) vs. at an early stage. From this table, we can clearly perceive that the survival is significantly improved when earlystage cancer can be diagnosed and then treated with existing therapies. Traditional screening methods for early diagnosis, such as Magnetic Resonance Imaging
(MRI), are often costly and not available for many people. Cancer biomarkers are molecules that can indicate the biological states of the disease, which increase in concentration during the onset of the disease (Phan et al., 2009). Sensitive and accurate detection of cancer biomarkers in human fluid samples could offer seminal contributions to early diagnosis. Therefore, the development of novel technologies that are capable of sensitively and selectively detect cancer biomarkers is crucially important.

Nanotechnology pertains to nanostructured materials or materials with nanostructured components that usually possess physical and chemical properties different from their bulk counterparts (Bonnell, 2010; Weiss, 2010). One intriguing benefit of nanotechnology involved in cancer diagnostics is the development of nanostructured materials-based detection systems can be applied to detect cancer biomarkers with an extremely high sensitivity and an ultralow Detection Limit (DL) (Heath and Davis, 2008; Nie et al., 2007). Corresponding Author: Rong Xiang, Department of Immunology, School of Medicine, Nankai University, Tianjin 300071, P. R. China 
Table 1. 5-year survival rates of four types of cancers diagnosed at the late stage vs. at an early stage. Data were summarized from the reference (Etzioni et al., 2003)

\begin{tabular}{|c|c|c|}
\hline & $\begin{array}{l}\text { Stage at diagnosis } \\
\text { Late }(\%)\end{array}$ & Early (\%) \\
\hline Lung cancer & 2 & 48 \\
\hline Colorectal cancer & 9 & 89 \\
\hline Breast cancer & 22 & 98 \\
\hline Prostate cancer & 32 & 100 \\
\hline
\end{tabular}

In this review, we summarize the use of various types of nanostructured materials in the detection of cancer biomarkers with an emphasis on research works published during the past three years. We classify these detection systems into two general categories: (1) heterogeneous systems and (2) homogeneous systems. A major difference between these two systems is whether or not a solid support is used to immobilize the cancer biomarkers for detection. Since the research of cancer biomarker detection is dominated by the use of heterogeneous systems, the main body of this review is comprised of studies relevant to heterogeneous systems. To more conveniently present the research progress, we further classify heterogeneous systems into two subcategories: (1) half-sandwich-type and (2) sandwich-type. We define the key difference between these two detection systems as whether or not a labeled probe is needed to complete the detection after immobilizing the biomarkers.

The classification of cancer biomarker detection systems in this review is depicted in Fig. 1. For the heterogeneous systems, this figure illustrates the case of immobilizing an antigen to a solid support through an antibody. It is known that cancer biomarkers can be substances other than just an antigen and the binding of these biomarkers may not be necessarily based on antigenantibody interactions. For example, the folate receptor is a prototypic cancer biomarker that is over expressed in many carcinoma cell lines. The folate receptor can be bound with either the folic acid or an anti-folate receptor antibody (Asati et al., 2009).

\subsection{Heterogeneous Systems: Half-Sandwich- Type}

So far, a variety of half-sandwich-type cancer biomarker detection systems have been developed. In these systems, the binding interactions between the biomarkers and the modified solid support can be often transduced into physically measurable signals. Due to the ability of performing rapid, label-free and multiplexed detection for many biomarkers, half-sandwich-type detection systems are becoming increasingly powerful tools in cancer diagnosis.

\subsubsection{Carbon Nanotubes (CNTs)}

CNTs, which were first discovered in 1991 (Iijima, 1991), are made up of graphene sheets rolled up into the shape of seamless tubular structure (Ji et al., 2010). CNTs can be structurally classified into two categories: single-wall CNTs, which consist of one layer of cylinder graphene and multi-wall CNTs, which contain multiple layers of concentric graphene cylinders (Sinha and Yeow, 2005).

In the past few years, there has been tremendous research effort focusing on the detection of cancer biomarkers using CNT-based sensors, which show high sensitivity and selectivity, as well as real-time response capabilities. Two different configurations, back-gated chemical Field-Effect Transistor (FET) and Chemiresistor (CR), have been adopted by most CNT-based sensors (Zhang et al., 2008). CNTs configured with FETs (hereafter referred to as CNT-FETs) are a threeelectrode system (Fig. 2a). The conductance between the source and drain electrodes is modulated by the gate electrode. In the CR configuration (Fig. 2b), CNTs bridge the positive and negative electrodes through which the current passes. In these sensors, receptor molecules with high specificity and strong binding affinity are anchored to the surface of CNTs to recognize the target biomarkers. Upon the binding of the biomarkers, the conductance of the semiconducting CNTs changes allowing them to sense biomarkers electrochemically (Choi et al., 2010). In general, FETs tend to be more sensitive than CRs due to their ability to tune the conductance of CNTs by controlling the gate voltage. This could explain why FET devices are more often seen in the literature. A diversity of CNT-FET devices has been developed for the cancer biomarker detection. Antibodymodified CNT-FETs are so far the most frequently used.

Prostate-Specific Antigen (PSA), a 28-kDa glycoprotein produced by the prostate gland and also a serine protease enzyme, has been used as a biomarker for the diagnosis and prognosis of prostate cancer (Lilja et al., 2008). In serum, PSA has been found either in a free form (fPSA) or as a complex with protease inhibitor alpha 1-antichymotrypsin (PSA-ACT complex). Total PSA (tPSA) refers to the sum of all detectable free and complexed PSA forms. A method for the detection of PSA-ACT complex using CNT-FET-based sensors was reported (Kim et al., 2009). Using 1pyrenebutanoic acid succinimidyl ester as the linker and 1-pyrenbutanol as the spacer, CNT-FETs have been modified with linkers and spacers of different ratios. 


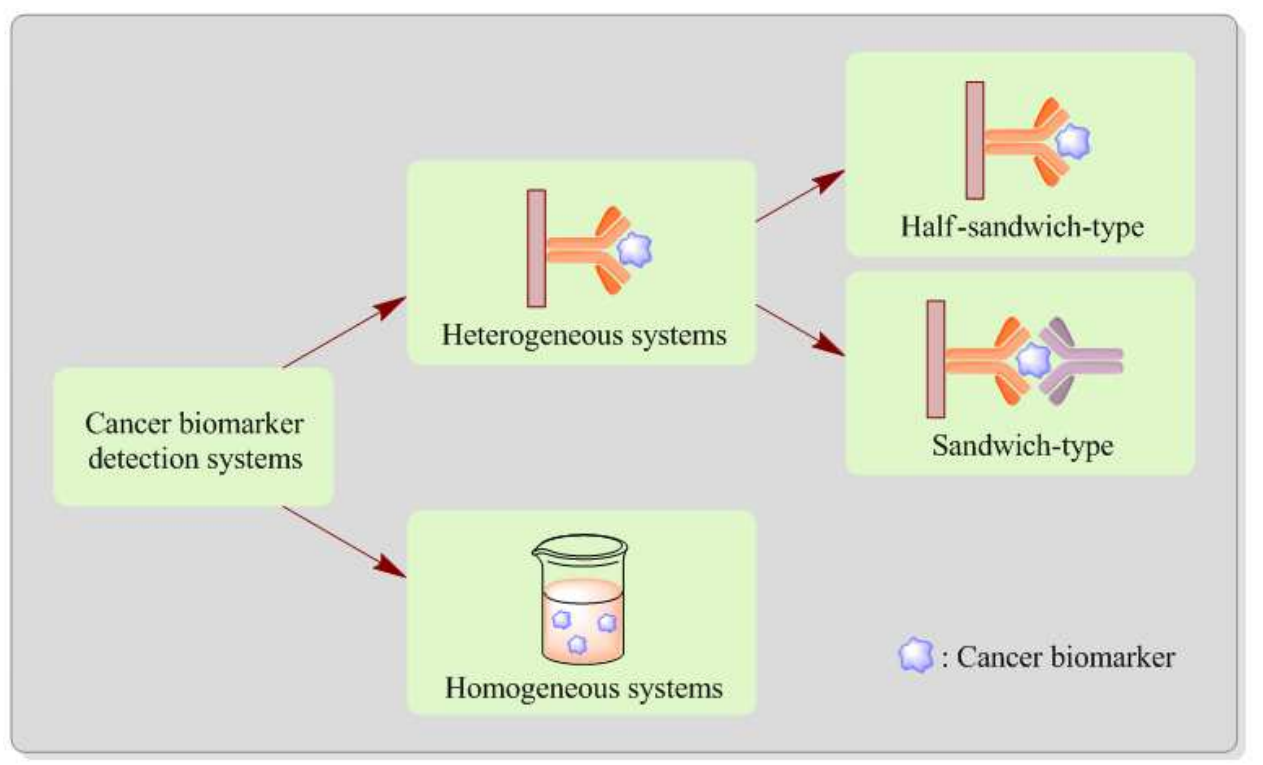

Fig. 1. Classification of cancer biomarker detection systems

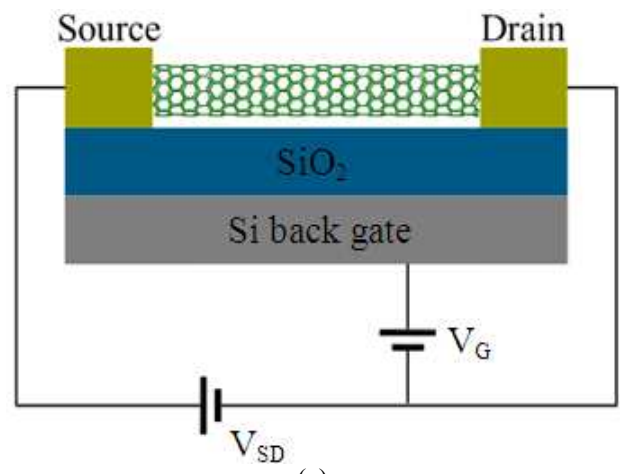

(a)

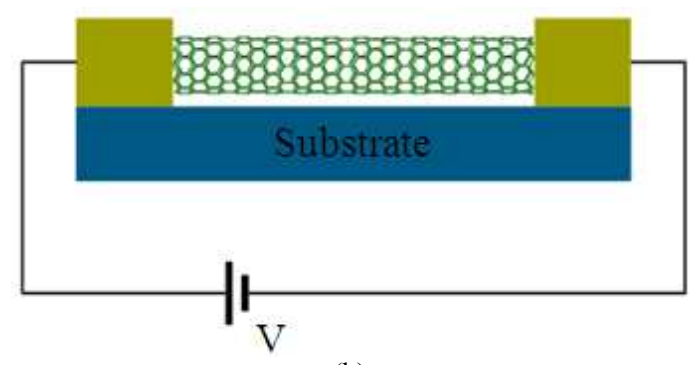

(b)

Fig. 2. Schematic diagrams of a CNT-FET (a) and a CNT-CR (b). $\mathrm{V}_{\mathrm{SD}}$ : source-drain voltage; $\mathrm{V}_{\mathrm{G}}$ : gate voltage

PSA-ACT complex antibodies were then immobilized on the CNT surface via the linkers. Results showed that CNT-FETs modified with only linkers could not detect target proteins unless more than $500 \mathrm{ng} \mathrm{mL}^{-1}$ of PSAACT complex solution was injected, while those modified with linkers and spacers of a 1-to-3 ratio could detect $1.0 \mathrm{ng} \mathrm{mL} \mathrm{m}^{-1}$ of PSA-ACT complex without any pretreatment. This study implies that modifying the CNT surface with a spacer could offer a useful strategy of improving the sensitivity of the device.

Insulin-like Growth Factor 1 (IGF-1) is a 70-amino acid polypeptide with a high degree of homology to insulin (Sachdev and Yee, 2001). The level of IGF-1 positively associates with breast cancer risk in women. Real-time detection of breast cancer cells using antibody-conjugated CNT-FETs was investigated (Teker, 2008). In this study, the conjugation of IGF-1 receptor-specific antibodies to CNT-FET devices caused a conductance decrease. Subsequent addition of BT474 or MCF7 breast cancer cells dramatically increased the conductance, demonstrating the possibility of detecting specific cell surface antigens on cancer cells using functionalized CNT-FETs. A later study compared radioimmunoassay and CNT-FET assay for measuring IGF-1 in a mouse model of human breast cancer (Jones et al., 2011). Results showed a good correlation between these two sensor platforms. Since CNT-FET assay requires only one antibody, it can provide real-time results with approximately 100 -fold less mouse serum than the radioimmunoassay.

Galectins, a family of proteins that bind $\beta$-galactosides, have been seriously implicated in tumor progression and 
metastasis and therefore have the potential to serve as reliable cancer biomarkers (Balan et al., 2010). A CNTFET device based on D-(+)-galactose-conjugated CNTs was fabricated and used to detect galectin-3 (Park et al., 2011). The primary effect of the binding of galectin-3 to CNTs was a charge-transfer reaction involving the donation of electrons from galectin-3 to CNTs. Therefore, the detection of galectin-3 was based on measuring the I-V difference occurred on the CNT surface when bound with galectin-3.

Osteopontin (OPN), a proinflammatory cytokine that regulates bone homeostasis through its effects on osteoclast function, is being investigated as a cancer biomarker (Sodek et al., 2000). The development of OPN detection method will help the disease diagnose and guide its treatment (Fedarko et al., 2001). A group of scientists from Philadelphia worked toward this goal by attaching a genetically engineered single-chain variable fragment $(\mathrm{scFv})$ protein with high binding affinity for OPN to a CNT-FET (Lerner et al., 2012). As low as $1 \mathrm{pg} \mathrm{mL}^{-1}$ of OPN could be detected, which was 3 orders of magnitude lower than the classical Enzyme-Linked Immunosorbent Assay (ELISA) method.

Lung cancer is the leading cause of cancer-related death both in men and women (Ferlay et al., 2010). In China, deaths due to lung cancer have increased $465 \%$ during the past 30 years (Zhao et al., 2010). However, current methods used to diagnose lung cancer may occasionally miss tumors. Due to its convenience, efficiency and low cost, the detection of Volatile Organic Compounds (VOCs) in exhaled human breath is becoming an important method for the widespread screening of lung cancer. FETs based on Random Networks (RNs) of CNTs exhibit distinctive physical properties. RN-CNT-FETs were prepared and functionalized with organic films in a recent work (Peng et al., 2009). High detection sensitivity of nonpolar VOCs was achieved by exposing functionalized RN-CNTs to decane, a nonpolar alkane hydrocarbon that has been used as an important breath biomarker of lung cancer and then monitoring the changes in conductance, work function and organic film thickness. CR devices based on the use of CNTs for the detection of VOCs to assist lung cancer diagnosis were also reported (Liu et al., 2011; Peng et al., 2008; Zilberman et al., 2010).

While the above literature reported the use of CNTs as successful sensors for a number of cancer biomarkers, sensing systems based on the combination of both CNTs and $\mathrm{In}_{2} \mathrm{O}_{3}$ nanowires were also investigated ( $\mathrm{Li}$ et al., 2005). An active channel that bridged the source/drain electrodes was made up of combined p-type CNTs and n-type $\mathrm{In}_{2} \mathrm{O}_{3}$ nanowires. To detect PSA, the nanochannel surface was functionalized with PSA antibody, which could give complementary electrical response upon PSA binding. The DL of PSA was achieved as low as $5 \mathrm{ng} \mathrm{mL}^{-1}$.

Mesothelin, a differentiation antigen normally present on mesothelial cells, is highly expressed in several human cancers including malignant mesothelioma, pancreatic, ovarian and lung adenocarcinoma. As a result, mesothelin has been evaluated as a diagnostic biomarker and an immunotherapeutic target (Wang et al., 2012). It is intriguing to note that a novel paper sensor aiming at the detection of mesothelin was recently invented (www.societyforscience.org/intelisef2012). The dispersion of antibody to human mesothelin and CNTs was used to dip-coat strips of filter paper to make them conductive. This paper sensor costs $\$ 3.00$ and 10 tests can be performed per strip. A test using this paper sensor just takes $5 \mathrm{~min}$.

\subsubsection{Silicon/Silica Nanomaterials}

Due to their tunable electrical property and excellent detection sensitivity, Silicon Nanowires (SiNWs) configured with FETs (hereafter referred to as SiNWFETs) have attracted enormous attention (Chen et al., 2011). Lieber and colleagues reported label-free, multiplexed electrical detection of cancer biomarkers using SiNW-FETs (Zheng et al., 2005). Specific antibodies were attached to the nanowire surface. These nanowire arrays allowed the detection of PSA, PSAACT complex, Carcinoembryonic Antigen (CEA) and

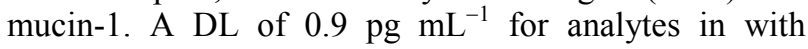
undiluted serum samples was achieved. To extend the diagnostic potential of SiNW-FETs, a nucleic acidbased marker assay involving the detection of telomerase was also explored. Telomerase, a eukaryotic ribonucleoprotein complex, is expressed in almost all human cancers ( $\mathrm{Xu}$ et al., 2011). Telomerase has been reported as a cancer biomarker for detection and targeted therapy. In this study, nucleic acid receptors enabled real-time assays of the binding, activity and small-molecule inhibition of telomerase using unamplified extracts from as few as ten tumor cells.

Vascular Endothelial Growth Factor (VEGF) is a signal protein produced by cells that stimulates the formation of new blood vessels (Takahashi and Shibuya, 2005). Label-free detection of VEGF for cancer diagnosis using anti-VEGF aptamer-modified SiNWFETs were reported (Lee et al., 2009). Due to the gating effect, the binding of VEGF to anti-VEGF aptamers depleted (accumulated) the charge carriers in the p-type 
(n-type) SiNW-FETs and thus decreased (increased) the detection currents. The DLs for VEGF in this study were determined as 1 and $0.1 \mathrm{nM}$ for the cases of n-type and p-type SiNW-FETs, respectively.

MicroRNA (miRNA) is a class of short noncoding RNAs that control gene expression in many cellular processes (Farazi et al., 2011). Rapid, sensitive and label-free detection for miRNA is of great significance, because miRNA could serve as an early marker of cancer. A direct hybridization assay for the ultrasensitive detection of miRNA using SiNW-FET device was developed (Zhang et al., 2009). Peptide nucleic acids, which served as a receptor to recognize miRNA directly without labeling the target miRNA, were immobilized on the nanowire surface. A DL of $1 \mathrm{fM}$ for the target miRNA was achieved via concentration-dependent measurements. In another study, SiNW-FETs were used to carry out label-free detection of the breast cancer serum biomarker protein CA 15-3 down to less than 20 $\mathrm{U} \mathrm{mL}^{-1}$, relevant for clinical use (Chen et al., 2010). This study extended the capability of SiNW sensors to a class of mucin-based heterogeneous protein biomarkers.

Silica Nanowires $\left(\mathrm{SiO}_{2}-\mathrm{NWs}\right)$, with their unique anisotropy in many physical properties, have been employed for developing biosensors with satisfied performance. Surface-Enhanced Raman Spectroscopy (SERS) has been increasingly used as a verification technique for the multiplexed biomarker analysis. Among the various SERS substrates used, the nanocluster $/ \mathrm{SiO}_{2}-\mathrm{NWs}$ configuration has the advantage of being engineered to grow on predetermined sites on a Si substrate, enabling the development of integrated microRaman detection on a chip. Antibody-modified nanocluster-functionalized $\mathrm{SiO}_{2}-\mathrm{NWs}$ were explored as SERS substrates for the detection of Interleukin-10 (IL10) (Sekhar et al., 2008a). A DL of $0.1 \mathrm{ng} \mathrm{mL}^{-1}$ for IL10 was obtained. To evaluate nonspecific binding, IL10 was attached to functionalized $\mathrm{SiO}_{2}$-NWs in the absence of antibodies. The absence of the IL-10 footprint around $2100 \mathrm{~cm}^{-1}$ suggested the inactive participation of IL-10 in the assay.

Besides the reports on the integration of CNTs and SiNWs into FETs as shown above, other kinds of nanomaterials-based FETs have also been developed for cancer biomarker detection through measuring electrical disturbances induced by the binding of these biomarkers. An FET biosensor based on the reduced Graphene Oxide (rGO)-encapsulated Silica Nanoparticles $\left(\mathrm{SiO}_{2}-\mathrm{NPs}\right)$ was developed to detect two breast cancer biomarkers: Human Epidermal growth factor Receptor 2 (HER2) and Epidermal Growth Factor Receptor (EGFR) (Myung et al.,
2011). The use of rGO-encapsulated $\mathrm{SiO}_{2}$-NPs in FETs is appealing due to its unique properties, such as the large surface area and the high thermal and chemical stability. The novel 3D structure of rGO-encapsulated $\mathrm{SiO}_{2}-\mathrm{NPs}$ tremendously increased the surface-to-volume ratio in this type of sensor. The DLs were $1 \mathrm{pM}$ for HER2 and $100 \mathrm{pM}$ for EGFR, which are significant improvements over thinfilm-transistor-type sensors based on graphene.

\subsubsection{Gold Nanomaterials}

Gold Nanorods (AuNRs) have been widely used for diagnosis due to their high scattering efficiency, low plasmon damping and the ability to tune their plasmon resonance by varying the aspect ratio. An ultrasensitive method for the attomolar detection of PSA-ACT complex was reported using Rayleigh light scattering spectroscopy of individual AuNRs sensors (Truong et al., 2012). By experimentally measuring the refractive index sensitivity of AuNRs, AuNRs with an aspect ratio of $\sim 3.5$ were proven optimal for the Localized Surface Plasmon Resonance (LSPR) sensing. To fabricate the sensors, AuNRs immobilized onto the glass substrate were conjugated with the PSA-ACT complex antibody. Using these sensors, the DL of PSA-ACT complex was $\sim 1$ aM, corresponding to LSPR $\lambda_{\max }$ shifts of $\sim 4.2 \mathrm{~nm}$. These results demonstrated the promising potential of individual AuNRs as biosensors for biomedical applications. For cancer biomarker detection using AuNRs in the absence of any substrate like the glass slide in this work, interested readers may refer to the later Section 1.3.1 of this review.

Nanoporous $\mathrm{Au}$ (NPAu) is a self-supporting 3D material containing nanometer-scale pores and has shown the usefulness in a wide range of applications. NPAu film-modified electrode was recently used in the construction of label-free immunosensors for PSA detection (Wei et al., 2011). Taking advantage of the large surface area of NPAu, a great amount of PSA antibodies could be absorbed into its pores. The sensing signal was based on monitoring the current response of $\mathrm{K}_{3} \mathrm{Fe}(\mathrm{CN})_{6}$ on the electrode, which was extremely sensitive to the immunocomplex formation. Under optimal conditions, a low DL of $3 \mathrm{pg} \mathrm{mL}^{-1}$ was achieved for PSA detection.

\subsubsection{Luminescent Nanomaterials}

Quantum Dots (QDs) are inorganic fluorophores that provide a great alternative to their organic counterparts. The past decade has witnessed a surge of applications of QDs in various fields of biomedical sciences, especially in vivo molecular imaging. In one work, QD-conjugated 
protein micro- and nanoarrays were fabricated and used for the detection of PSA (Gokarna et al., 2008). Results supported that QD-protein conjugated hybrid structures in micro- and nanoarrays showed usefulness for cancer biomarker detection, wherein QDs play a role in the imaging and screening of different types of cancer.

Electrochemiluminescence (ECL) is a kind of luminescence produced during electrochemical reactions. Since the first observation of silicon nanocrystal ECL in 2002 (Ding et al., 2002), ECL of QDs, especially II-VI semiconductors such as $\mathrm{CdS}, \mathrm{CdSe}$ and $\mathrm{ZnSe}$, has been investigated for the development of novel labels for ECL detection. As one of the most widely used cancer biomarkers, CEA is present in normal mucosal cells but increased amounts are associated with gastrointestinal cancers, especially in colorectal malignancy (Duffy, 2001). To detect CEA, an ECL immunosensor was fabricated via a multi-step procedure (Jie et al., 2011). The key step in the fabrication of the sensor was the coating of $\mathrm{Fe}_{3} \mathrm{O}_{4}$ nanoparticles with $\mathrm{CdSe}-\mathrm{CdS}$ nanoparticles. These nanocomposite materials could be conveniently and firmly attached to the magnetic electrode. Gold Nanoparticles (AuNPs) were then assembled on the electrode, which further improved the ECL signal, because AuNPs accelerated the electron transfer in the ECL reaction. Finally, after immobilizing antibodies on the electrode, Bovine Serum Albumin (BSA) was added to block all nonspecific binding sites of the immunosensor. This sensor exhibited intense and stable ECL emissions in neutral solution making it ideal for ECL immunosensing. The ECL mechanism can be described with Equation 1-4 as below (Myung et al., 2002):

$$
\begin{aligned}
& \mathrm{CdSe}-\mathrm{CdS}+\mathrm{e}^{-} \rightarrow \mathrm{CdSe}-\mathrm{CdS}^{-} \\
& \mathrm{S}_{2} \mathrm{O}_{8}{ }^{2-}+\mathrm{e}^{-} \rightarrow \mathrm{SO}_{4}{ }^{2-}+\mathrm{SO}_{4}^{--} \\
& \mathrm{CdSe}-\mathrm{CdS}^{--}+\mathrm{SO}_{4}^{--} \rightarrow \mathrm{CdSe}-\mathrm{CdS}^{*}+\mathrm{SO}_{4}{ }^{2-} \\
& \mathrm{CdSe}-\mathrm{CdS}^{*} \rightarrow \mathrm{CdSe}-\mathrm{CdS}+\mathrm{h} v
\end{aligned}
$$

The ECL peak intensities gradually decreased with increasing CEA concentrations. This could be explained by the formation of an immunocomplex, which increased the steric hindrance. This compromised the above ECL process, leading to decreased ECL intensities. An ultralow DL of $32 \mathrm{fg} \mathrm{mL}^{-1}$ for CEA was achieved.

\subsubsection{Other Nanomaterials \\ 1.1.5.1. Polymer Nanowires}

Conducting polymers have shown strong promise as materials for sensor applications due to their tunable electrical properties and environmentally benign synthetic routes. A cost-effective method to fabricate and assemble single conducting Polypyrrole Nanowire (PPyNW)-based biosensors for CA 125 detection was developed (Bangar et al., 2009). PPy-NWs were aligned across a pair of gold electrodes separated by a gap of 3 $\mu \mathrm{m}$. PPy-NWs were surface-functionalized with CA 125 antibodies. The immunosensor had excellent sensitivity with a DL of $1 \mathrm{U} \mathrm{mL}^{-1}$ for CA 125 in $10 \mathrm{mM}$ phosphate buffer. Furthermore, there was no loss of performance upon exposure to CA 125 in spiked human blood plasma.

\subsubsection{Metal Nanoislands}

Metal nanoislands are ultrafine particles of a few to several hundred metal atoms and hence exhibit a huge surface-to-volume ratio, which makes them useful for highly sensitive biomarker detection. Nickel Nanoislands (NiNIs) are especially interesting due to the possible stable attachment of proteins on their surfaces. A technique for the label-free detection and recognition of cancer biomarkers using NiNI-based biosensors was described (Martinez-Rivas et al., 2010). The antibody fragment His-tagged (scFv)-F7N1N2 was directly immobilized onto $\sim 5 \mathrm{~nm}$ NiNIs through a histidine tag and then deposited on the surface of a quartz crystal of a Quartz Crystal Microbalance (QCM). Biomarker GTPase RhoA, which has been found overexpressed in various tumors, was chosen for the test. Results supported the possibility of using NiNIs as an anchoring surface layer to sense the biomarker conformation.

\subsubsection{Nanostructured Microelectrodes (NMEs)}

Cancer biomarker detection based on electronic readout has long been cited as a promising approach. The miniaturization of electrochemical systems has drawn enormous attention from electroanalytical and materials scientists. In an NME, a larger portion of atoms is located at the electrode surface as compared to a planar electrode. Thus, NMEs possess various advantages over conventional macroelectrodes, such as the enhancement of mass-transport rates and the control over electrode microenvironment. The detection of nucleic acid biomarkers offers valuable diagnostic and prognostic information for cancer management. Researchers from Canada reported the use of a novel NME chip to detect a group of gene fusions specific to prostate cancer in both cell extracts and tumor tissues (Fang et al., 2009). Gene fusions that correlate with aggressive prostate cancer were identified and distinguished from those associated with slower progressing forms of the disease. This NME system represents an attractive 
alternative to PCR-based methods that are sensitive but difficult to automate in a clinical setting.

\subsection{Heterogeneous Systems: Sandwich-Type}

Sandwich-type detection methods are widely adopted in cancer diagnosis. For a typical sandwich-type detection system, a Capture Antibody (hereafter referred to as $A b_{1}$ ) against a particular biomarker is first immobilized on a plate. After the binding of antigen from a sample solution, a Secondary Antibody (hereafter referred to as $A b_{2}$ ) is allowed to bind with the immobilized antigen. The concentration of the antigen can then be determined by indirectly measuring the concentration of the probe attached to $\mathrm{Ab}_{2}$. It may be mentioned that the immobilization of cancer biomarkers may not through antigen-antibody interactions. According to our previous definition, as long as a labeled probe is still needed to complete the detection after immobilizing the biomarkers, we consider this detection system as the sandwich-type.

While half-sandwich-type detection systems described in the Section 1.1 are attractive in that they eliminate the need of $\mathrm{Ab}_{2}$, sandwich-type detection systems also have benefits. For example, the employment of a multi-label strategy could contribute to enhanced sensitivity and selectivity. In the following context, research progress on sandwich-type detection systems based on the use of various kinds of nanostructured materials is presented.

\subsubsection{CNTs}

Liver cancer is a serious type of cancer that causes death more often than many other tumors. In men, it is the fifth most frequently diagnosed cancer worldwide, but also the second most common cause of cancer death (Kim and Han, 2012). The poor outcome of patients with liver cancer is primarily attributed to the late diagnosis. Alpha-Fetoprotein (AFP) is the most widely used serological marker in the early detection of liver cancer. A signal amplification strategy for the enhanced Chemiluminescence (CL) detection of AFP was developed (Bi et al., 2009). CL is the emission of light as the result of a chemical reaction. A typical CL system is luminol- $\mathrm{H}_{2} \mathrm{O}_{2}$-Horseradish Peroxidase (HRP), in which HRP-catalyzed reaction between luminol and $\mathrm{H}_{2} \mathrm{O}_{2}$ produces CL. It is already known that numerous phenol derivatives can enhance luminol- $\mathrm{H}_{2} \mathrm{O}_{2}-\mathrm{HRP}$ CL (Diaz et al., 1995). In this work, bromophenol blue was used as the enhancer of the chemiluminescent luminol- $\mathrm{H}_{2} \mathrm{O}_{2}-\mathrm{HRP}$ reaction. A feature of this study is the fabrication of HRP multilayers on CNTs through the layer-by-layer assembly technique. With more enzyme layers assembled on CNTs, the biocatalytic activity could be increased. A low DL of $8.0 \mathrm{pg} \mathrm{mL}^{-1}$ for AFP was obtained supporting the effectiveness of the enzyme multilayer-based signal amplification strategy.

Besides CL-based detection methods, ECL-based detection methods were also found attractive. Although ECL is a form of CL, there is a major difference between $\mathrm{CL}$ and ECL on how to control a light emission. In CL, luminescence is governed by merely mixing suitable reagents. In contrast, the light emission is controlled by turning on/off the electrode potential in ECL. As a bioanalytical technique, ECL is considered advantageous over CL. The $\mathrm{Ru}(\text { bpy })_{3}{ }^{2+}$ (bpy $=2,2^{\prime}$-bipyridine) or its derivatives with tripropylamine exhibit the highest ECL efficiency and this system forms the basis of many commercial systems for immunoassay (Miao et al., 2002). Using labels immobilized with $\mathrm{Ru}(\mathrm{bpy})_{3}{ }^{2+}$, a sandwich-type ECL immunosensor for AFP detection was fabricated (Hou et al., 2011). To greatly enhance the detection sensitivity, CNT-Ru(bpy) ${ }_{3}{ }^{2+}$ complex was prepared and $\mathrm{Ru}(\mathrm{bpy})_{3}{ }^{2+}$-labeled $\mathrm{Ab}_{2}$ was further immobilized onto the above complex. The final magnetic sandwich-type complexes can be adsorbed on a planar Screen-Printed Carbon Electrode (SPCE) under an externally added magnetic field. This ECL immunosensor showed a low DL of $3 \mathrm{pg} \mathrm{mL}^{-1}$ for AFP.

The above studies lay out the strategies useful for AFP detection. However, the detection of only one type of cancer biomarkers could possibly give false results. Therefore, accurate detection of multiple biomarkers is always required to confirm the diagnosis of cancers. An electrochemical immunosensor for simultaneous detection of three liver cancer biomarkers, AFP, Alpha-Fetoprotein variants (AFP-L3) and Abnormal Prothrombin (APT) was investigated (Li et al., 2012). Three electrochemical redox species, ferrocene, $\mathrm{CoL}_{3}{ }^{3+}\left(\mathrm{L}=2,2^{\prime}\right.$ '-bipyridine-4,4'dicarboxylic acid) and thionine, with distinct voltammetric peaks were used to label three different antibodies as signal tags. The electrochemical signals were simultaneously obtained at different peak potentials and the positions and the sizes of these peaks reflected the identities and levels of the corresponding biomarkers. To improve the signal response, CNTs coated with AuNPs were used to immobilize these redox probe-labeled antibodies. Results showed that the DLs for AFP, AFP-L3 and APT were 8.3, 4.7 and $6.0 \mathrm{pg} \mathrm{mL}^{-1}$, respectively.

Simultaneous detection of two cancer biomarkers, PSA and Interleukin-8 (IL-8) was also reported (Wan et al., 2011). A disposable SPCE array was used as the detection platform. A noteworthy point in this study is the 
fabrication of a multi-labeled nanoprobe by immobilizing HRP and goat anti-rabbit IgG on CNTs. Considering that goat anti-rabbit IgG can bind to rabbit antibodies, this multi-labeled nanoprobe can be used to detect any target antigen in the presence of unlabeled rabbit antibodies that serve as a binding bridge. By using this electrochemical immunosensor, the DLs of $5 \mathrm{pg}$ $\mathrm{mL}^{-1}$ for PSA and $8 \mathrm{pg} \mathrm{mL}{ }^{-1}$ for IL- 8 were achieved.

4-Chloro-1-Naphthol (4C1N) is a HRP substrate; in the presence of $\mathrm{H}_{2} \mathrm{O}_{2}$, this substrate produces insoluble precipitates, which is blue in color and can be observed visually. By enhanced precipitation of $4 \mathrm{C} 1 \mathrm{~N}$ using a higher number of HRP molecules attached on CNTs, a signal amplification strategy was developed to detect PSA (Akter et al., 2012). The conjugation of more HRP molecules with $\mathrm{Ab}_{2}$ through CNTs could result in a decrease of the electroactive area of the electrode, thus enhancing the current reduction of the redox probe. Under optimized experimental conditions, the DL of PSA was determined to be $0.40 \mathrm{pg} \mathrm{mL}^{-1}$.

Glycans refer to polysaccharides or oligosaccharides, which can be found attached to proteins on the exterior surface of cells. Glycans play important roles in many biological events and their abnormal expression has been shown to correlate with cancers (Adamczyk et al., 2012). A lectin-based electrochemical biosensor was fabricated for the competitive assay of glycan expression on living cancer cells (Zhang et al., 2011). Mannose present on human lung cancer cells (95-D and H1299) was used as a model glycan. Concanavalin A (Con A), a mannosespecific lectin with four sugar-binding pockets, was used to prepare a Con A-based biosensor for mannose detection. To amplify the signals, AuNPs were attached to CNTs in the presence of thionine, which could be used to immobilize thiomannosyl dimers resulting in the formation of the CNT/thionine/AuNP-mannose nanocomposites. These nanocomposites could compete effectively with cell surface mannose to recognize the biosensor surface-confined Con A. In this study, the differential pulse voltammetric response was proportional to the mannose concentration $\left(\mathrm{C}_{\text {mannose }}\right)$. Therefore, the amount of mannose on each cell surface $\mathrm{N}_{\text {mannose }}\left(=\mathrm{C}_{\text {mannose }} \times 6.02 \times 10^{23}\right)$ could be calculated. The average amounts of mannose on a single cell surface were found to be $2.8 \times 10^{8}$ molecules for each 95 -D cell and $3.1 \times 10^{10}$ molecules for each $\mathrm{H} 1299$ cell.

Besides the wide application of CNTs in biosensing, Carbon Nanoparticles (CNPs) also display advantageous features owing to the tunability of the particle size and shape. A sandwich-type electrochemical immunosensor that uses $A b_{1}$-attached graphene sheets and $H R P-A b_{2}-$ labeled CNPs was developed for detecting AFP (Du et al., 2010). This immunosensor showed a 7-fold increase in detection signals compared to the immunosensor without graphene modification and CNPs labeling, giving a DL of $0.02 \mathrm{ng} \mathrm{mL}^{-1}$ for AFP.

\subsubsection{CNT Forests}

CNT forests, termed by Rusling et al. (2009) and colleagues, are $20 \sim 30 \mathrm{~nm}$ terminally carboxylated single-wall CNTs self-assembled in upright bundles. As a new type of nanostructured sensor surface, CNT forests have shown 4 10-fold increases in the detection sensitivity of cancer biomarkers over sensors built on bare pyrolytic graphite surface. Efficient and direct electrical communication was largely possible between the highly conductive CNTs in these forests and peroxidase enzymes bioconjugated to their ends. The combination of electrochemical immunosensors using $\mathrm{CNT}$ forests with multi-labeled $\mathrm{Ab}_{2}-\mathrm{CNT}$ bioconjugates for highly sensitive detection of PSA in serum and tissue lysates was reported (Yu et al., 2006). Greatly amplified sensitivity was attained by using bioconjugates featuring HRP labels and $A b_{2}$ linked to CNTs at high $\mathrm{HRP} / \mathrm{Ab}_{2}$ ratio. This approach provided a DL of $4 \mathrm{pg} \mathrm{mL}^{-1}$ for PSA in $10 \mu \mathrm{L}$ of undiluted calf serum.

A later work reported the use of a CNT forest-based immunoarray for the simultaneous detection of PSA, Prostate-Specific Membrane Antigen (PSMA), Platelet Factor-4 (PF-4) and Interleukin-6 (IL-6) in a single serum sample (Chikkaveeraiah et al., 2009). $\mathrm{Ab}_{2}$ was labeled with HRP, which could give a large catalytic amperometric reduction signal when activated by $\mathrm{H}_{2} \mathrm{O}_{2}$ using a quinone mediator. Although conventional singly labeled $\mathrm{Ab}_{2}$-HRP conjugates were sufficient for PSA and PSMA detection, the detection of clinically relevant levels of PF-4 and IL-6 required higher sensitivity. Thus, a strategy involving the use of biotinylated $\mathrm{Ab}_{2}$ that specifically binds to a streptavidin-HRP bioconjugate was utilized to provide 14-16 labels on each $\mathrm{Ab}_{2}$. These immunoarrays accurately detected all four biomarkers in human serum samples of prostate cancer patients, while requiring only $40-\mu \mathrm{L}$ samples, $2-10$ times less than the commercial assays, such as the ELISA.

Head and Neck Squamous Cell Carcinoma (HNSCC) is associated with immune, inflammatory and angiogenic responses involving IL-6. An ultrasensitive electrochemical immunosensor for human IL-6 detection in HNSCC cells was reported (Malhotra et al., 2010). CNT forests with attached $A b_{1}$ for IL- 6 were combined with the use of the enzyme label HRP to measure very low $\left(\leq 30 \mathrm{pg} \mathrm{mL}^{-1}\right)$ and elevated levels of IL-6. Two levels of multienzyme 
labeling were used to measure a broad concentration range of IL- 6 in a representative panel of HNSCC cells. $\mathrm{Ab}_{2}$ attached to carboxylated CNTs with $106 \mathrm{HRP}$ labels per $100-\mathrm{nm}$ CNT gave an ultralow DL of $0.5 \mathrm{pg} \mathrm{mL}^{-1}$ for IL-6 in $10 \mu \mathrm{L}$ of calf serum. The DL using $\mathrm{Ab}_{2}-\mathrm{CNT}-\mathrm{HRP}$ is 16 -fold better than that of the $\operatorname{ELISA}\left(8 \mathrm{pg} \mathrm{mL}^{-1}\right)$.

Dye-doped silica nanoparticles represent a class of materials that show attractive applications as labels in ultrasensitive ECL assays. An electrochemiluminescent sandwich immunosensor for the detection of cancer biomarker PSA using $\mathrm{Ab}_{1}$-conjugated $\mathrm{CNT}$ forests and $\mathrm{Ab}_{2}$-conjugated $\mathrm{Ru}(\mathrm{bpy})_{3}{ }^{2+}$-doped silica nanoparticles was investigated (Sardesai et al., 2009). ECL can be produced in a multi-step catalytic redox process using $\operatorname{Pr}_{3} \mathrm{~N}$ (tripropylamine, TPA) as the sacrificial reductant to yield photoexcited $\left[\mathrm{Ru}(\mathrm{bpy})_{3}{ }^{2+}\right]^{*}$ that emits light at $\sim 610 \mathrm{~nm}$. This ECL mechanism can be described with Equation 5-9 as below (Miao et al., 2002):

$$
\begin{aligned}
& \operatorname{Pr}_{3} \mathrm{~N} \rightarrow \mathrm{Pr}_{3} \mathrm{~N}^{+}+\mathrm{e}^{-} \\
& \mathrm{Pr}_{3} \mathrm{~N}^{++} \rightarrow \mathrm{Pr}_{2} \mathrm{NC}^{-} \mathrm{HCH}_{2} \mathrm{CH}_{3}+\mathrm{H}^{+} \\
& \mathrm{Ru}(\text { bpy })_{3}{ }^{2+}+\mathrm{Pr}_{2} \mathrm{NC} \cdot \mathrm{HCH}_{2} \mathrm{CH}_{3} \rightarrow \\
& \mathrm{Ru}(\text { bpy })_{3}^{+}+\mathrm{Pr}_{2} \mathrm{~N}^{+}=\mathrm{CHCH}_{2} \mathrm{CH}_{3} \\
& \mathrm{Ru}(\text { bpy })_{3}^{+}+\mathrm{Pr}_{3} \mathrm{~N}^{++} \rightarrow\left[\mathrm{Ru}(\text { bpy })_{3}{ }^{2+}\right] *+\mathrm{Pr}_{3} \mathrm{~N} \\
& {\left[\mathrm{Ru}(\text { bpy })_{3}{ }^{2+}\right] * \rightarrow \mathrm{Ru}(\text { bpy })_{3}{ }^{2+}+\mathrm{h} v}
\end{aligned}
$$

ECL depends on the radicals derived from TPA. It is worthy of noting that the permeation of TPA through the protein film to the sensor surface may be controlled by steric hindrance of excess $A b_{1}$ on the surface. Research showed that the inclusion of surfactants in the electrolyte with TPA resulted in a 10 -fold increase in ECL relative to the use of TPA alone. Since it is known that CNTs adsorb surfactants, it is likely that this treatment increased the hydrophobicity of the sensor surface via an adsorbed hydrophobic layer, which facilitates oxidation of TPA. Using this immunosensor, a DL of $40 \mathrm{pg} \mathrm{mL}^{-1}$ for PSA was obtained.

In a later study, an ECL immunosensor array featuring $\mathrm{Ab}_{1}$-conjugated $\mathrm{CNT}$ forests residing in the bottoms of $10-\mu \mathrm{L}$ wells with hydrophobic polymer walls was fabricated and used to capture analyte proteins
(Sardesai et al., 2011). Silica nanoparticles labeled with both $\mathrm{Ru}(\mathrm{bpy})_{3}{ }^{2+}$ and $\mathrm{Ab}_{2}$ are employed in this system for the highly sensitive detection of two analytes. Results showed that the DL was $1 \mathrm{pg} \mathrm{mL}^{-1}$ for PSA and was 0.25 pg mL $\mathrm{mL}^{-1}$ for IL-6 in serum. ECL arrays with CNT forest microwells provide a simple and sensitive approach to the detection of multiple proteins.

\subsubsection{Gold Nanomaterials}

Breast cancer is the most commonly diagnosed cancer in women worldwide (Place et al., 2011). The chance of a woman having breast cancer sometime during her life is about 1 in 8. CA 15-3, a mucinassociated antigen, is an important biomarker present in blood samples and is useful for determining diagnosis, prognosis and monitoring therapy of breast cancer. A sandwich-type ELISA for the analysis of CA 15-3 was developed (Ambrosi et al., 2010). AuNPs were used as the carriers of $\mathrm{Ab}_{2}$-HRP in order to amplify the optical signals. The use of AuNPs as signal enhancers not only resulted in a doubled sensitivity, but also shortened the incubation time from $30 \mathrm{~min}$ of the classical procedure to $5 \mathrm{~min}$ of this work for the color development. These results conceptually proved that AuNPs could be used successfully to enhance the performances of traditional ELISA tests, achieving higher sensitivities and therefore more confident results.

Although there is a nonnegligible risk of prostate cancer at any PSA level, the normal range of PSA levels is regarded to be $0 \sim 4 \mathrm{ng} \mathrm{mL}^{-1}$ (Thompson et al., 2004). The increase in PSA levels above the normal limit (4 ng $\mathrm{mL}^{-1}$ ) is directly associated with an increased risk of prostate cancer. A sensitive method was developed for the detection of PSA and PSA-ACT complex in human serum by using $\mathrm{Ab}_{1}$-modified $\mathrm{QCM}$ sensor and $\mathrm{Ab}_{2}$-modified AuNPs amplification system (Uludag and Tothill, 2010). A DL of $0.29 \mathrm{ng} \mathrm{mL}^{-1}$ for PSA and PSA-ACT complex (in $75 \%$ serum) was obtained.

The detection of PSA using a label-free optical biosensor could provide a quick test in contrast to the conventional ELISA tests. One of the most common labelfree optical techniques used for biomolecular interaction detection is Surface Plasmon Resonance (SPR). A pointof-care immunosensor for the detection of tPSA using SPR and QCM sensor platforms in human serum samples was developed (Uludag and Tothill, 2012). With the use of $40 \mathrm{~nm}$ AuNPs, a DL of $0.29 \mathrm{ng} \mathrm{mL}^{-1}$ for tPSA was obtained in $75 \%$ human serum. The SPR sensor results were found to be comparable to that achieved using a QCM sensor platform, indicating that both systems can be applied for cancer biomarkers screening. 
Inkjet printing offers an inexpensive non-contact fabrication method for microelectronics. Inkjet-printed AuNP arrays were fabricated and applied to the detection of IL-6 in serum (Jensen et al., 2011). The AuNP ink was printed on a flexible, heat resistant polyimide Kapton substrate and subsequently sintered to create eight-electrode arrays costing less than $\$ 0.25$ per array. IL-6 $A b_{1}$ was linked onto the eight-electrode array and used in the sandwich-type immunoassays. A biotinylated $\mathrm{Ab}_{2}$ with 16-18 HRP labels was used and the detection was achieved by hydroquinone-mediated amperometry. The arrays provided a clinically relevant DL of $20 \mathrm{pg}$ $\mathrm{mL}^{-1}$ for IL-6 in calf serum.

Cytokeratin-7 (CK-7), a protein expressed in the epithelial tissue, has shown usefulness as a cancer biomarker in discriminating primary from metastatic adenocarcinoma (Tot, 2002). In one study, ultrasensitive electrochemical detection of CK-7 using Gold Nanowire (AuNW)-based biosensor was reported (Patil et al., 2008). To prepare a sandwich-type immunosensor system, $A b_{1}$ was immobilized onto AuNWs, while streptavidin-conjugated Alkaline Phosphatase (AP) was bound to biotinylated $\mathrm{Ab}_{2}$. The enzymatic reaction between AP and p-nitrophenyl phosphate resulted in an electroactive p-nitrophenol, which could be detected electrochemically using microelectrodes. The resulting anodic peak current was directly proportional to AP concentrations and in turn could be correlated with the concentrations of CK-7.

\subsubsection{Luminescent Nanomaterials}

The use of advanced detection methodologies, such as fluorescent QDs, promises to help detect cancer biomarkers. The integration of fluorescent QDs into a microfluidic biosensor for the multiplexed quantification of CEA, CA 125 and Her2/neu was studied (Jokerst et al., 2009). The utilization of QD probes significantly contributed to the signal amplification and the decrease of the DL. Taking CEA as an example, the DLs of CEA were $0.02 \mathrm{ng} \mathrm{mL}^{-1}$ in this QD-based system, $2.61 \mathrm{ng}$ $\mathrm{mL}^{-1}$ when this system was replaced with an Alexa Fluor 488 signaling method and $1.20 \mathrm{ng} \mathrm{mL}^{-1}$ in the ELISA. To the authors' best knowledge, this was the first paper in which QDs provided quantitative cancer biomarker information using blood or salivary clinical samples.

IL-10, an anti-inflammatory cytokine, is associated with lung cancer survival (Enewold et al., 2009). IL-10 at a concentration of $100 \mu \mathrm{g} \mathrm{mL}^{-1}$ was detected through a fluorescent diagnostic system containing QD-655 as the fluorescent tag (Sekhar et al., 2008b). The use of IgY antibodies and QDs to improve cancer biomarker detection and quantification was also investigated (Xiao and Gao, 2010).

Gastric cancer is the second leading cause of cancerrelated death worldwide (Hsu et al., 2010). A real-time detection of gastric cancer-associated biomarkers in the lumen of the stomach could assist in the early detection of this multi-step malignancy. A microarray-type system was designed for the specific recognition of Alpha 1Antitrypsin (A1AT), a secreted biomarker, after its being captured by the immobilized trypsin (Khazanov et al., 2012). To amplify the optical detection signals, the ELISA-type assays that typically employ fluorescently labeled antibodies was replaced by fluorescently labeled polymer nanoparticles, which fluoresce in the nearinfrared region. Such labels have the advantage of generating minimal tissue background fluorescence. To eventually detect A1AT, fluorescent nanoparticles were modified with antibodies specific to A1AT. Results suggested the feasibility of using this sensor system as a real time diagnostic kit for the detection of a secreted gastric cancer biomarker.

\subsubsection{Magnetic Nanomaterials}

Many types of cancer biomarker detection systems employ surface-functionalized magnetic nanomaterials to recognize specific molecular targets (Koh and Josephson, 2009). Due to their biocompatibility, superior magnetic properties and stability, Iron Oxide Nanoparticles (IONPs), have been applied in a wide range of areas, such as MRI, cell labeling and biosensing. A sensor system for the detection of PSA using IONPs was described (Li et al., 2011b). To fabricate this sandwichtype immunosensor, $A b_{1}$-conjugated IONPs were used as the capture moiety, while both $\mathrm{Ab}_{2^{-}}$and HRPconjugated IONPs were used to bind with the immobilized PSA. This sensor system displayed a low DL of $4 \mathrm{pg} \mathrm{mL} \mathrm{m}^{-1}$ for PSA.

Another study also described the use of a sandwich-type immunosensor for PSA detection using IONPs (Li et al., 2011a). Due to its high redox activity, ferrocene has been widely used as a mediator for enzyme based biosensors and as a label for DNA and protein detection. In this work, $A b_{1}$ was immobilized onto the Graphene Sheet (GS) surface, while both $\mathrm{Ab}_{2}$ and ferrocene were conjugated to IONPs. The signal of this immunosensor was mainly from the redox current of ferrocene on IONPs. A low DL of 2 pg mL $\mathrm{mL}^{-1}$ for PSA was achieved.

Recently, a densely packed AuNP platform combined with a multi-labeled $\mathrm{Ab}_{2}$-Magnetic Bead 
(MB) bioconjugate was used as to detect PSA in serum (Mani et al., 2009). Sensitivity was greatly amplified by synthesizing magnetic bioconjugates particles containing $7500 \mathrm{HRP}$ labels. This sensor gave a DL of $0.5 \mathrm{pg} \mathrm{mL} \mathrm{m}^{-1}$ for PSA in $10 \mu \mathrm{L}$ of undiluted serum. Measurements of PSA in cell lysates and human serum of cancer patients gave excellent correlations with the standard ELISA assays. In another work, the clustering of MB labels on the SPR sensor surface led to unprecedented sensitivity and ultralow DL for PSA in serum (Krishnan et al., 2011). To fabricate the sensor, $\mathrm{Ab}_{1}$ was covalently immobilized onto carboxylatefunctionalized Au-SPR chips, while SPR was monitored continuously after the injection of the MB$\mathrm{Ab}_{2}$-PSA bioconjugates. An ultralow DL of $10 \mathrm{fg} \mathrm{mL}^{-1}$ for PSA was obtained.

A nanostructured amperometric sensor electrode coated with a dense film of $A b_{1}$-attached AuNPs to detect IL-8 was reported (Munge et al., 2011). When coupled to superparamagnetic beads massively loaded with about 500,000 HRP labels and $\mathrm{Ab}_{2}$, an ultralow DL of $1.0 \mathrm{fg} \mathrm{mL}$ (30,000-fold lower than that of the conventional ELISA) for IL-8 in serum was achieved.

An ultrasensitive electrochemical microfluidic array optimized to measure a four-protein panel of biomarker proteins was reported (Malhotra et al., 2012). This assay required only $50 \mathrm{~min}$ and $5 \mu \mathrm{L}$ of the serum. Ultralow detection into the $5 \sim 50 \mathrm{fg} \mathrm{mL}^{-1}$ range was achieved for simultaneous measurement of IL-6, IL-8, VEGF and VEGF-C in diluted serum. Off-line capture of analyte proteins by MBs carrying 400,000 HRP labels and $\sim 100,000 \mathrm{Ab}_{2}$ facilitated the ultrasensitive response of the microfluidic array. These immunoarrays were then used to validate a four-biomarker protein panel for oral cancer by analyzing 78 serum samples from oral cancer patients and 49 cancer-free controls. Statistical analysis indicated clinical specificity of $98 \%$ and sensitivity of $89 \%$ for oral cancer detection based on normalized means of the four-protein assays.

There is a constant need to develop biomolecular detection tools for the sensitive, multiplexed and easily implementable detection of cancer biomarkers. The above-mentioned MBs are large particles, which have a diameter of approximately $1 \mu \mathrm{m}$. These particles are not optimal for biomolecular assays, as they diffuse slowly and are very bulky compared with the analyte molecules. To overcome these limitations, 50-nm Magnetic Nanotags (MNTs) which are commercially available from Miltenyi Biotec have attracted researchers' attention due to their long-term suspension stability and excellent binding selectivity. By labeling the analyte of interest with MNTs, analyte detection and quantification can occur when the analyte binds to capture probes on the surface of giant magnetoresistive sensors. A number of analytes were chosen for the MNTbased biomarker assays (Osterfeld et al., 2008). With the addition of MNT amplification, the detection sensitivity could be extended to the low $\mathrm{fM}$ concentration range.

\subsubsection{Other Nanomaterials}

\subsubsection{Cerium Oxide Nanoparticles (CONPs)}

The reliable and sensitive detection of cancer biomarkers is important for the diagnosis and treatment of cancer. In traditional sandwich-type ELISA, an HRPlabeled $\mathrm{Ab}_{2}$ is utilized to assess the binding of a specific $A b_{1}$ to a particular target. This binding event is assessed by the ability of HRP oxidizing a certain substrate in the presence of $\mathrm{H}_{2} \mathrm{O}_{2}$. However, the employment of labile components, such as HRP and $\mathrm{H}_{2} \mathrm{O}_{2}$, is a limitation of this method due to the possible denaturing of HRP and decomposition of $\mathrm{H}_{2} \mathrm{O}_{2}$ under certain circumstances.

CONPs have an intrinsic oxidase-like activity at acidic $\mathrm{pH}$ values, as it can quickly oxidize various colorimetric dyes at acidic $\mathrm{pH}$, such as 3,3',5,5'tetramethylbenzidine, without any oxidizing agent. On the basis of this property, Perez and colleagues designed an immunoassay in which folate-conjugated CONPs provided dual functionality by binding to folate-expressing cancer cells and facilitating detection by catalytic oxidation of sensitive colorimetric dyes (Asati et al., 2009). Folate-CONPs-dependent binding was observed for the lung carcinoma cell line (A-549) that overexpresses the folate receptor, as judged by an increase in absorbance at $652 \mathrm{~nm}$ with an increasing amount of folate-CONPs. Control experiments were done using cardiac myocytes (H9c2) that did not overexpress the folate receptor.

CONPs-based colorimetric ELISA outperforms the traditional ELISA, which requires $\mathrm{H}_{2} \mathrm{O}_{2}$ to facilitate the dye oxidation. However, one drawback of the CONPsbased colorimetric ELISA is that the oxidation of the dye by CONPs is optimal in acidic conditions, limiting the use of antibodies and other $\mathrm{pH}$-labile biomolecules as targeting ligands. Therefore, detection at neutral $\mathrm{pH}$ would be ideal to advance the wide application of this method. A chromophore that develops a stable fluorescence upon oxidation by CONPs, particularly at neutral $\mathrm{pH}$, would be ideal for developing a more robust nanoceria-based ELISA. Sensitive fluorigenic detection of cancer biomarkers at neutral $\mathrm{pH}$ using CONPs was 
reported (Asati et al., 2011). Investigation reveled that CONPs could oxidize the nonfluorescent substrate ampliflu, either to the very stable fluorescent product resorufin at $\mathrm{pH} 7.0$ or to the nonfluorescent resazurin at $\mathrm{pH}$ 4.0. Taking advantage of this interesting finding, the authors incorporated Protein $\mathrm{G}$ to immobilize antibodies on the surface of CONPs, in order to detect the expression of cancer biomarkers, such as the folate receptor and the epithelial cell adhesion molecule, at $\mathrm{pH}$ 7.0. It was found that within $3 \mathrm{~h}$, CONPs identified the expression of these biomarkers on carcinoma cells, while the traditional ELISA had a readout time of $15 \mathrm{~h}$.

\subsubsection{Nanoporous Materials}

Nanoporous materials represent a continued research focus of nanotechnology (Zhang et al., 2013). A natural function that nanoporous materials can offer to biosensing is apparently that they can act as an effective filer of biomolecules with sizes larger than the pore diameter. A nanoporous membrane-based filtering and sensing platform for cancer biomarker detection in whole blood without any sample preparation was reported (Escosura-Muniz and Merkoci, 2011). Anodic aluminum oxide that consists of hexagonally ordered nanoporous arrays was used as the template for sensor fabrication in this work. During the experiment, the constituents of the blood (probably red blood cells, white blood cells, platelets and crystal salts, all on the micrometric scale) were found remaining on the surface of the membrane, while the biomarker molecules could enter inside and were recognized by specific antibodies. This interesting blocking effect was further enhanced by silver deposition, which decreased the diffusion of the signaling indicator through the nanoporous channels. This novel sensor system was capable of detecting up to $52 \mathrm{U} \mathrm{mL}^{-1}$ of $\mathrm{CA} 15-3$.

\subsection{Homogeneous Systems}

In the context above, the wide use of heterogeneous assays in cancer biomarker detection has been described. However, a traditional heterogeneous assay is still timeconsuming and labor-intensive due to the requirements of multiple steps of incubation, separation and washing before signal measurement. From the initial antibody immobilization to the final reading of the assay results, the entire assay can usually take hours to days to complete. The development of single-step, washing-free homogeneous assays as an attractive alternative to heterogeneous assays has been of tremendous interest to the scientific community.

\subsubsection{AuNPs}

Dynamic Light Scattering (DLS) is a technique that is based on the scattering of light by moving particles. DLS has been popularly employed to determine the particle size distribution in a fluid (Alexander and Dalgleish, 2006). AuNPs scatter light intensely at or near their surface plasmon wavelength region. There has been a highly sensitive one-step homogeneous immunoassay developed for PSA detection using AuNP probes coupled with the DLS analysis (Liu et al., 2008). In this study, two different types of AuNPs (spherical nanoparticles and nanorods) were conjugated with a PSA antibody pair. When mixing these two bioconjugated nanoparticles with fPSA, it was observed the formation of dimers, oligomers or aggregates of nanoparticles through the binding of fPSA. Through DLS analysis, the relative ratio of nanoparticle dimers, oligomers or aggregates vs. individual nanoparticles were measured quantitatively, providing an accurate homogeneous immunoassay method.

In a later work, the same technique was used in different tissue lysate samples to examine four cancer biomarkers: CEA, CA 125, CA 19-9 and Prostatic Acid Phosphatase (PAP) (Huo, 2010). The PAP assay results of prostate tissue samples deserve particular note. PAP levels are known to be elevated in both prostate cancer and noncancerous diseases such as Benign Prostate Hyperplasia (BPH). Using current molecular tests, prostate cancer cannot be distinguished from other non-cancerous diseases. In this study, based on the complex/aggregation level of PAP in prostate tissue lysates, prostate cancer can be successfully distinguished from BPH. These results reveal the potential value of using protein complexes/aggregates as the biomarkers for cancer diagnosis and prognosis.

Serum is a type of blood plasma that contains various proteins and this may cause significant interference to light scattering technique-based assays. By taking advantage of the exceptionally strong scattering intensity of AuNPs, multiple molecular aberrations associated with prostate cancer from both mouse and human blood serum samples were discovered (Huo et al., 2011). It was further found that compared to samples from healthy and benign conditions, the level of VEGF adsorbed to the AuNPs decreased in cancer samples. It is generally believed that in the blood of cancer patients, the level of VEGF is often elevated. Therefore, to explain this contradictory finding, the authors postulated that the VEGF detected here is complexed with serum proteins, not the typical individual VEGF proteins as detected using other existing immunoassay methods. 
A very recent work that deserves particular note concerns the detection of PSA using plasmonic nanosensors, which exhibit inverse detection sensitivity (Rodriguez-Lorenzo et al., 2012). The novelty of this work is that the authors designed a particular and interesting system, in which $\mathrm{H}_{2} \mathrm{O}_{2}$, generated by glucose oxidase, reduced silver ions to grow a silver coating around plasmonic nanosensors (gold nanostars). By controlling the kinetics of silver nanocrystal growth with an enzyme, the inverse detection sensitivity was possible and this in turn determined the signal registered by the plasmonic transducer. Unprecedented sensitivity of this approach was demonstrated by detecting PSA down to $10^{-18} \mathrm{~g} \mathrm{~mL}^{-1}$ in whole serum.

Nucleic acids that exhibit catalytic properties (DNAzymes) have attracted an increasing interest in recent years. An immunoassay strategy for the detection of AFP using DNAzyme-functionalized AuNPs as catalytic labels was reported (Zhou et al., 2009). A sandwich-type detection strategy was employed using two types of probes. One was magnetic microparticles functionalized with AFP monoclonal antibodies. The other was AuNPs heavily functionalized with doublestranded DNA strands (only one strand was attached to AuNPs, the complementary strand was peroxidasemimicking DNAzyme) and AFP polyclonal antibodies. After the formation and the following magnetic collection of the sandwiched complex, the doublestranded DNA strands on AuNPs were dehybridized. The released DNAzyme units subsequently reacted with the substrate solution including a chromogenic reagent that showed green color in the presence of DNAzyme catalysis. A DL of $0.1 \mathrm{ng} \mathrm{mL}^{-1}$ for AFP was obtained using this immunoassay.

\subsubsection{Silver Nanoparticles (AgNPs)}

Functionalization of noble metal nanoparticles with DNA oligonucleotides has led to the development of novel analytical tools based on SPR, metalenhanced/quenched fluorescence and SERS for the detection of nucleic acid targets of interest. Unique optical and plasmonic properties of metal nanoparticles are utilized as signal transducers for reporting oligonucleotide hybridization events. Multiplexed detection of breast cancer biomarkers in a homogeneous solution using SERS-based Molecular Sentinel (MS) technology was demonstrated recently (Wang and Vo-Dinh, 2009). Two MS nanoprobes, ERBB2-MS and KI67-MS, were designed to respectively target critical biomarkers for breast cancer, e.g., erbB-2 gene and Ki-67 gene. The MS nanoprobe consisted of a Raman-labeled DNA hairpin probe and an AgNP. In the presence of the complementary target DNA, the hairpin conformation of the MS nanoprobe was disrupted and the SERS signal was significantly reduced due to the physical separation of the Raman label from the surface of the AgNP. This study demonstrated the feasibility of using multiple MS nanoprobes for multiplexed cancer biomarker detection.

Fluorescence Correlation Spectroscopy (FCS) is an ultrasensitive optical technique that measures the concentrations, mobilities and interactions of fluorescent biomolecules within a very small detection volume (Ries and Schwille, 2012). In a recent work, a highly sensitive homogeneous immunoassay by combining FCS with AgNP-antibody conjugates as probes was developed to detect AFP (Tang et al., 2010). Compared to AFP, the AFP-antibody complexes showed a significant increase in diffusion times and fluorescence intensities. Under the optimal conditions, the DL was $1.5 \mathrm{pM}$ for AFP.

\section{CONCLUSION}

In pursuit of novel methods for cancer diagnosis, nanotechnology has been proved to be a highly promising field. In this review, recent research and development of cancer biomarker detection using a variety of nanostructured materials-based sensors has been summarized. Functionalized carbon nanotubes, silicon nanowires, gold nanoparticles, quantum dots and many other kinds of nanomaterials-based sensors can offer a higher sensitivity and a better selectivity compared to traditional sensors. It is expected that the ultralow DLs obtained by a number of detection systems could substantially contribute to the early diagnosis and accurate prognosis of cancers.

The impact of nanotechnology on the fundamental research and clinical treatment of cancer can never be underestimated. Besides the field of cancer biomarker detection reviewed herein, nanotechnology has also been actively involved in the following fields: (1) cancer biomarker identification (Fredolini et al., 2010), (2) cancer imaging and treatment (Choi et al., 2012), (3) cancer metastasis (Schroeder et al., 2012) and (4) cancer stem cell research (Vinogradov and Wei, 2012). Researchers with different backgrounds and experiences are working together in this exciting forefront area toward the same ultimate goal: turning cancer into a curable disease, benefiting mankind. 


\section{ACKNOWLEDGEMENT}

This study was supported by the National Basic Research Program of China (973 Program, No. 2013CB967201), the National Natural Science Foundation of China (No. 30830096) and the Key Project of Tianjin Scientific and Technological Commission for China-Sweden Cooperation Research Program (No. 09ZCZDSF04000).

\section{REFERENCES}

Adamczyk, B., T. Tharmalingam and P.M. Rudd, 2012. Glycans as cancer biomarkers. BBA-Gen. Subjects, 1820: 1347-1353. DOI: 10.1016/j.bbagen.2011.12.001

Akter, R., M.A. Rahman and C.K. Rhee, 2012. Amplified electrochemical detection of a cancer biomarker by enhanced precipitation using horseradish peroxidase attached on carbon nanotubes. Anal. Chem., 84: 6407-6415. DOI: 10.1021/ac300110n

Alexander, M. and D.G. Dalgleish, 2006. Dynamic light scattering techniques and their applications in food science. Food Biophys., 1: 2-13. DOI: 10.1007/s11483-005-9000-1

Ambrosi, A., F. Airo and A. Merkoci, 2010. Enhanced gold nanoparticle based ELISA for a breast cancer biomarker. Anal. Chem., 82: 1151-1156. DOI: 10.1021/ac902492c

Asati, A., C. Kaittanis, S. Santra and J.M. Perez, 2011. pH-tunable oxidase-like activity of cerium oxide nanoparticles achieving sensitive fluorigenic detection of cancer biomarkers at neutral $\mathrm{pH}$. Anal. Chem., 83: 2547-2553. DOI: 10.1021/ac102826k

Asati, A., S. Santra, C. Kaittanis, S. Nath and J.M. Perez, 2009. Oxidase-like activity of polymer-coated cerium oxide nanoparticles. Angew. Chem. Int. Ed., 48: 2308-2312. DOI: 10.1002/anie. 200805279

Balan, V., P. Nangia-Makker and A. Raz, 2010. Galectins as cancer biomarkers. Cancers, 2: 592610. DOI: $10.3390 /$ cancers2020592

Bangar, M.A., D.J. Shirale, W. Chen, N.V. Myung and A. Mulchandani, 2009. Single conducting polymer nanowire chemiresistive label-free immunosensor for cancer biomarker. Anal. Chem., 81: 2168-2175. DOI: $10.1021 / \mathrm{ac} 802319 \mathrm{f}$
Bi, S., H. Zhou and S. Zhang, 2009. Multilayers enzymecoated carbon nanotubes as biolabel for ultrasensitive chemiluminescence immunoassay of cancer biomarker. Biosens. Bioelectron., 24: 29612966. DOI: 10.1016/j.bios.2009.03.002

Bonnell, D., 2010. The next decade of nanoscience and nanotechnology. ACS Nano, 4: 6293-6294. DOI: $10.1021 / \mathrm{nn} 102952 \mathrm{y}$

Chen, K.I., B.R. Li and Y.T. Chen, 2011. Silicon nanowire field-effect transistor-based biosensors for biomedical diagnosis and cellular recording investigation. Nano Today, 6: 131-154. DOI: 10.1016/j.nantod.2011.02.001

Chen, Y., X. Wang, M.K. Hong, C.L. Rosenberg and B.M. Reinhard et al., 2010. Nanoelectronic detection of breast cancer biomarker. Appl. Phys. Lett., 97: 233702. DOI: 10.1063/1.3519983

Chikkaveeraiah, B.V., A. Bhirde, R. Malhotra, V. Patel and J.S. Gutkind et al., 2009. Single-wall carbon nanotube forest arrays for immunoelectrochemical measurement of four protein biomarkers for prostate cancer. Anal. Chem., 81: 9129-9134. DOI: 10.1021/ac9018022

Choi, K.Y., G. Liu, S. Lee and X. Chen, 2012. Theranostic nanoplatforms for simultaneous cancer imaging and therapy: Current approaches and future perspectives. Nanoscale, 4: 330-342. DOI: 10.1039/c1nr11277e

Choi, Y.E., J.W. Kwak and J.W. Park, 2010. Nanotechnology for early cancer detection. Sensors, 10: 428-455. DOI: $10.3390 / \mathrm{s} 100100428$

Craene, B.D. and G. Berx, 2013. Regulatory networks defining EMT during cancer initiation and progression. Nat. Rev. Cancer, 13: 97-110. DOI: $10.1038 / \mathrm{nrc} 3447$

Diaz, A.N., F. Garcia Sanchez and J.A. Gonzalez Garcia, 1995. Chemical indicators as enhancers of the chemiluminescent luminol- $\mathrm{H}_{2} \mathrm{O}_{2}$-horseradish peroxidase reaction. J. Photochem. Photobiol. A., 87: 99-103. DOI: 10.1016/1010-6030(94)03970-6

Ding, Z., B.M. Quinn, S.K. Haram, L.E. Pell and B.A. Korgel et al., 2002. Electrochemistry and electrogenerated chemiluminescence from silicon nanocrystal quantum dots. Science, 296: 1293-1297. DOI: $10.1126 /$ science. 1069336

Du, D., Z. Zou, Y. Shin, J. Wang and H. Wu et al., 2010. Sensitive immunosensor for cancer biomarker based on dual signal amplification strategy of graphene sheets and multienzyme functionalized carbon nanospheres. Anal. Chem., 82: 2989-2995. DOI: $10.1021 / \mathrm{ac} 100036 \mathrm{p}$ 
Duffy, M.J., 2001. Carcinoembryonic antigen as a marker for colorectal cancer: Is it clinically useful? Clin. Chem., 47: 624-630. PMID: 11274010

Eheman, C., S.J. Henley, R. Ballard-Barbash, E.J. Jacobs and M.J. Schymura et al., 2012. Annual Report to the Nation on the status of cancer, 1975-2008, featuring cancers associated with excess weight and lack of sufficient physical activity. Cancer, 118: 2338-2366. DOI: 10.1002/cncr.27514

Enewold, L., L.E. Mechanic, E.D. Bowman, Y.L. Zheng and $\mathrm{Z}$. Yu et al., 2009. Serum concentrations of cytokines and lung cancer survival in African Americans and Caucasians. Cancer Epidemiol. Biomarkers Prev., 18: 215-222. DOI: 10.1158/10559965.EPI-08-0705

Escosura-Muniz, A.D.L. and A. Merkoci, 2011. A nanochannel/nanoparticle-based filtering and sensing platform for direct detection of a cancer biomarker in blood. Small, 7: 675-682. DOI: 10.1002/smll.201002349

Etzioni, R., N. Urban, S. Ramsey, M. McIntosh and S. Schwartz et al., 2003. The case for early detection. Nat. Rev. Cancer, 3: 243-252. DOI: $10.1038 / \mathrm{nrc} 1041$

Fang, Z., L. Soleymani, G. Pampalakis, M. Yoshimoto and J.A. Squire et al., 2009. Direct profiling of cancer biomarkers in tumor tissue using a multiplexed nanostructured microelectrode integrated circuit. ACS Nano, 3: 3207-3213. DOI: 10.1021/nn900733d

Farazi, T.A., J.I. Spitzer, P. Morozov and T. Tuschl, 2011. MiRNAs in human cancer. J. Pathol., 223: 102-115. DOI: $10.1002 /$ path.2806

Fedarko, N.S., A. Jain, A. Karadag, M.R. Van Eman and L.W. Fisher, 2001. Elevated serum bone sialoprotein and osteopontin in colon, breast, prostate and lung cancer. Clin. Cancer Res., 7: 4060-4066. PMID: 11751502

Ferlay, J., H.R. Shin, F. Bray, D. Forman and C. Mathers et al., 2010. Estimates of worldwide burden of cancer in 2008: GLOBOCAN 2008. Int. J. Cancer, 127: 2893-2917. DOI: 10.1002/ijc. 25516

Fredolini, C., F. Meani, A. Luchini, W. Zhou and P. Russo et al., 2010. Investigation of the ovarian and prostate cancer peptidome for candidate early detection markers using a novel nanoparticle biomarker capture technology. AAPS J., 12: 504518. DOI: $10.1208 / \mathrm{s} 12248-010-9211-3$
Gokarna, A., L.H. Jin, J.S. Hwang, Y.H. Cho and Y.T. Lim et al., 2008. Quantum dot-based protein microand nanoarrays for detection of prostate cancer biomarkers. Proteomics, 8: 1809-1818. DOI: 10.1002/pmic. 200701072

Heath, J.R. and M.E. Davis, 2008. Nanotechnology and cancer. Annu. Rev. Med., 59: 251-265. DOI: 10.1146/annurev.med.59.061506.185523

Hou, J.G., N. Gan, F.T. Hu, L. Zheng and Y.T. Cao et al., 2011. One renewable and magnetic electrochemiluminescence immunosensor based on tris(2,2'-bipyridine) ruthenium(II) modified magnetic composite nanoparticles labeled anti-AFP. Int. J. Electrochem. Sci., 6: 2845-2858.

Hsu, P.I., C.H. Chen, M. Hsiao, D.C. Wu and C.Y. Lin et al., 2010. Diagnosis of gastric malignancy using gastric juice $\alpha 1$-antitrypsin. Cancer Epidemiol. Biomarkers Prev., 19: 405-411. DOI: 10.1158/10559965.EPI-09-0609

Huo, Q., 2010. Protein complexes/aggregates as potential cancer biomarkers revealed by a nanoparticle aggregation immunoassay. Colloid. Surface. B, 78: 259-265. DOI: 10.1016/j.colsurfb.2010.03.012

Huo, Q., J. Colon, A. Cordero, J. Bogdanovic and C.H. Baker et al., 2011. A facile nanoparticle immunoassay for cancer biomarker discovery. J. Nanobiotechnol., 9: 20-31. DOI: $10.1186 / 1477-3155-9-20$

Iijima, S., 1991. Helical microtubules of graphitic carbon. Nature, 354: 56-58. DOI: 10.1038/354056a0

Jensen, G.C., C.E. Krause, G.A. Sotzing and J.F. Rusling, 2011. Inkjet-printed gold nanoparticle electrochemical arrays on plastic. Application to immunodetection of a cancer biomarker protein. Phys. Chem. Chem. Phys., 13: 4888-4894. DOI: 10.1039/c0cp01755h

Ji, S.R., C. Liu, B. Zhang, F. Yang and J. Xu et al., 2010. Carbon nanotubes in cancer diagnosis and therapy. BBA-Rev. Cancer, 1806: 29-35. DOI: 10.1016/j.bbcan.2010.02.004

Jie, G., L. Wang and S. Zhang, 2011. Magnetic electrochemiluminescent $\quad \mathrm{Fe}_{3} \mathrm{O}_{4} / \mathrm{CdSe}-\mathrm{CdS}$ nanoparticle/polyelectrolyte nanocomposite for highly efficient immunosensing of a cancer biomarker. Chem. Eur. J., 17: 641-648. DOI: 10.1002/chem.201001128

Jokerst, J.V., A. Raamanathan, N. Christodoulides, P.N. Floriano and A.A. Pollard et al., 2009. Nano-biochips for high performance multiplexed protein detection: Determinations of cancer biomarkers in serum and saliva using quantum dot bioconjugate labels. Biosens. Bioelectron., 24: 3622-3629. DOI: 10.1016/j.bios.2009.05.026 
Jones, L.P., S. Stefansson, M.S. Kim and S.N. Ahn, 2011. Comparison of radioimmuno and carbon nanotube field-effect transistor assays for measuring insulin-like growth factor-1 in a preclinical model of human breast cancer. J. Nanobiotechnol., 9: 36-41. DOI: 10.1186/1477-3155-9-36

Khazanov, E., E. Yavin, A. Pascal, A. Nissan and Y. Kohl et al., 2012. Detecting a secreted gastric cancer biomarker molecule by targeted nanoparticles for real-time diagnostics. Pharm. Res., 29: 983-993. DOI: $10.1007 / \mathrm{s} 11095-011-0638-8$

Kim, D.Y. and K.H. Han, 2012. Epidemiology and surveillance of hepatocellular carcinoma. Liver Cancer, 1: 2-14. DOI: 10.1159/000339016

Kim, J.P., B.Y. Lee, J. Lee, S. Hong and S. J. Sim, 2009. Enhancement of sensitivity and specificity by surface modification of carbon nanotubes in diagnosis of prostate cancer based on carbon nanotube field effect transistors. Biosens. Bioelectron., 24: 3372-3378. DOI: 10.1016/j.bios.2009.04.048

Koh, I. and L. Josephson, 2009. Magnetic nanoparticle sensors. Sensors, 9: 8130-8145. DOI: $10.3390 / \mathrm{s} 91008130$

Krishnan, S., V. Mani, D. Wasalathanthri, C.V. Kumar and J.F. Rusling, 2011. Attomolar detection of a cancer biomarker protein in serum by surface plasmon resonance using superparamagnetic particle labels. Angew. Chem. Int. Ed., 50: 1175-1178. DOI: 10.1002/anie. 201005607

Lee, H.S., K.S. Kim, C.J. Kim, S.K. Hahn and M.H. Jo, 2009. Electrical detection of VEGFs for cancer diagnoses using anti-vascular endotherial growth factor aptamer-modified Si nanowire FETs. Biosens. Bioelectron., 24: 1801-1805. DOI: 10.1016/j.bios.2008.08.036

Lerner, M.B., J. D'Souza, T. Pazina, J. Dailey and B.R. Goldsmith et al., 2012. Hybrids of a genetically engineered antibody and a carbon nanotube transistor for detection of prostate cancer biomarkers. ACS Nano, 6: 5143-5149. DOI: $10.1021 / \mathrm{nn} 300819 \mathrm{~s}$

Li, C., M. Curreli, H. Lin, B. Lei and F.N. Ishikawa et al., 2005. Complementary detection of prostatespecific antigen using $\operatorname{In}_{2} \mathrm{O}_{3}$ nanowires and carbon nanotubes. J. Am. Chem. Soc., 127: 12484-12485. DOI: $10.1021 / \mathrm{ja} 053761 \mathrm{~g}$

Li, H., Q. Wei, G. Wang, M. Yang and F. Qu et al., 2011b. Sensitive electrochemical immunosensor for cancer biomarker with signal enhancement based on nitrodopamine-functionalized iron oxide nanoparticles. Biosens. Bioelectron., 26: 3044-3049. DOI: $10.1016 /$ j.bios.2010.12.011
Li, H., Q. Wei, J. He, T. Li and Y. Zhao et al., $2011 \mathrm{a}$. Electrochemical immunosensors for cancer biomarker with signal amplification based on ferrocene functionalized iron oxide nanoparticles. Biosens. Bioelectron., 26: 3590-3595. DOI: 10.1016/j.bios.2011.02.006

Li, Y., Z.Y. Zhong, Y.Q. Chai, Z.J. Song and Y. Zhuo et al., 2012. Simultaneous electrochemical immunoassay of three liver cancer biomarkers using distinguishable redox probes as signal tags and gold nanoparticles coated carbon nanotubes as signal enhancers. Chem. Commun., 48: 537-539. DOI: 10.1039/c1cc14886a

Lilja, H., D. Ulmert and A.J. Vickers, 2008. Prostatespecific antigen and prostate cancer: Prediction, detection and monitoring. Nat. Rev. Cancer, 8: 268278. DOI: $10.1038 / \mathrm{nrc} 2351$

Liu, F.L., P. Xiao, H.L. Fang, H.F. Dai and L. Qiao et al., 2011. Single-walled carbon nanotube-based biosensors for the detection of volatile organic compounds of lung cancer. Physica E, 44: 367-372. DOI: 10.1016/j.physe.2011.08.033

Liu, X., Q. Dai, L. Austin, J. Coutts and G. Knowles et al., 2008. A one-step homogeneous immunoassay for cancer biomarker detection using gold nanoparticle probes coupled with dynamic light scattering. J. Am. Chem. Soc., 130: 2780-2782. DOI: $10.1021 /$ ja $711298 b$

Malhotra, R., V. Patel, B.V. Chikkaveeraiah, B.S. Munge and S.C. Cheong et al., 2012. Ultrasensitive detection of cancer biomarkers in the clinic by use of a nanostructured microfluidic array. Anal. Chem., 84: 6249-6255. DOI: 10.1021/ac301392g

Malhotra, R., V. Patel, J.P. Vaque, J.S. Gutkind and J.F. Rusling, 2010. Ultrasensitive electrochemical immunosensor for oral cancer biomarker IL-6 using carbon nanotube forest electrodes and multilabel amplification. Anal. Chem., 82: 3118-3123. DOI: 10.1021/ac902802b

Mani, V., B.V. Chikkaveeraiah, V. Patel, J.S. Gutkind and J.F. Rusling, 2009. Ultrasensitive immunosensor for cancer biomarker proteins using gold nanoparticle film electrodes and multienzymeparticle amplification. ACS Nano, 3: 585-594. DOI: 10.1021/nn800863w

Martinez-Rivas, A., P. Chinestra, G. Favre, S. Pinaud and C. Severac et al., 2010. Detection of label-free cancer biomarkers using nickel nanoislands and quartz crystal microbalance. Int. J. Nanomed., 5: 661-668. DOI: 10.2147/ijn.s12188 
Miao, W.J., J.P. Choi and A.J. Bard, 2002. Electrogenerated chemiluminescence 69: the tris(2,2'-bipyridine)ruthenium(II), $\left(\mathrm{Ru}(\mathrm{bpy}){ }_{3}{ }^{2+}\right) /$ tri- $n$-propylamine $\quad(\mathrm{TPrA})$ system revisited - A new route involving $\operatorname{TPrA}^{+}$cation radicals. J. Am. Chem. Soc., 124: 14478-14485. DOI: $10.1021 / \mathrm{ja} 027532 \mathrm{v}$

Munge, B.S., A.L. Coffey, J.M. Doucette, B.K. Somba and R. Malhotra et al., 2011. Nanostructured immunosensor for attomolar detection of cancer biomarker interleukin-8 using massively labeled superparamagnetic particles. Angew. Chem. Int. Ed., 50: 7915-7918. DOI: 10.1002/anie.201102941

Myung, N., Z.F. Ding and A.J. Bard, 2002. Electrogenerated chemiluminescence of $\mathrm{CdSe}$ nanocrystals. Nano Lett., 2: 1315-1319. DOI: $10.1021 / \mathrm{nl} 0257824$

Myung, S., A. Solanki, C. Kim, J. Park and K.S. Kim et al., 2011. Graphene-encapsulated nanoparticlebased biosensor for the selective detection of cancer biomarkers. Adv. Mater., 23: 2221-2225. DOI: 10.1002/adma.201100014

Nie, S., Y. Xing, G.J. Kim and J.W. Simons, 2007. Nanotechnology applications in cancer. Annu. Rev. Biomed. Eng., 9: 257-288. DOI: 10.1146/annurev.bioeng.9.060906.152025

Osterfeld, S.J., H. Yu, R.S. Gaster, S. Caramuta and L. $\mathrm{Xu}$ et al., 2008. Multiplex protein assays based on real-time magnetic nanotag sensing. Proc. Natl. Acad. Sci. USA., 105: 20637-20640. DOI: 10.1073/pnas.0810822105

Park, Y.K., B. Bold, W.K. Lee, M.H. Jeon and K.H. An et al., 2011. D-(+)-Galactose-conjugated singlewalled carbon nanotubes as new chemical probes for electrochemical biosensors for the cancer marker galectin-3. Int. J. Mol. Sci., 12: 2946-2957. DOI: 10.3390/ijms 12052946

Patil, S.J., A. Zajac, T. Zhukov and S. Bhansah, 2008. Ultrasensitive electrochemical detection of cytokeratin-7, using Au nanowires based biosensor. Sensor Actuat. B, 129: 859-865. DOI: 10.1016/j.snb.2007.09.080

Peng, G., E. Trock and H. Haick, 2008. Detecting simulated patterns of lung cancer biomarkers by random network of single-walled carbon nanotubes coated with nonpolymeric organic materials. Nano Lett., 8: 3631-3635. DOI: 10.1021/n1801577u
Peng, G., U. Tisch and H. Haick, 2009. Detection of nonpolar molecules by means of carrier scattering in random networks of carbon nanotubes: Toward diagnosis of diseases via breath samples. Nano Lett., 9: 1362-1368. DOI: 10.1021/nl8030218

Phan, J.H., R.A. Moffitt, T.H. Stokes, J. Liu and A.N. Young et al., 2009. Convergence of biomarkers, bioinformatics and nanotechnology for individualized cancer treatment. Trends Biotechnol., 27: 350-358. DOI: 10.1016/j.tibtech.2009.02.010

Place, A.E., S.J. Huh and K. Polyak, 2011. The microenvironment in breast cancer progression: Biology and implications for treatment. Breast Cancer Res., 13: 227-237. DOI: 10.1186/bcr2912

Ries, J. and P. Schwille, 2012. Fluorescence correlation spectroscopy. Bioessays, 34: 361-368. DOI: 10.1002/bies.201100111

Rodriguez-Lorenzo, L., R.D.L. Rica, R.A. AlvarezPuebla, L.M. Liz-Marzan and M.M. Stevens, 2012. Plasmonic nanosensors with inverse sensitivity by means of enzyme-guided crystal growth. Nat. Mater., 11: 604-607. DOI: 10.1038/nmat3337

Rusling, J.F., G. Sotzing and F. Papadimitrakopoulosa, 2009. Designing nanomaterial-enhanced electrochemical immunosensors for cancer biomarker proteins. Bioelectrochemistry, 76: 189194. DOI: 10.1016/j.bioelechem.2009.03.011

Sachdev, D. and D. Yee, 2001. The IGF system and breast cancer. Endocr. Relat. Cancer, 8: 197-209. DOI: $10.1677 /$ erc.0.0080197

Sardesai, N., S.M. Pan and J. Rusling, 2009. Electrochemiluminescent immunosensor for detection of protein cancer biomarkers using carbon nanotube forests and $\left[\mathrm{Ru}-(\mathrm{bpy})_{3}\right]^{2+}$-doped silica nanoparticles. Chem. Commun., 45: 4968-4970. DOI: $10.1039 / \mathrm{b} 909220 \mathrm{j}$

Sardesai, N.P., J.C. Barron and J.F. Rusling, 2011. Carbon nanotube microwell array for sensitive electrochemiluminescent detection of cancer biomarker proteins. Anal. Chem., 83: 6698-6703. DOI: $10.1021 / \mathrm{ac} 201292 \mathrm{q}$

Schroeder, A., D.A. Heller, M.M. Winslow, J.E. Dahlman and G.W. Pratt et al., 2012. Treating metastatic cancer with nanotechnology. Nat. Rev. Cancer, 12: 39-50. DOI: 10.1038/nrc3180

Sekhar, P.K., N.S. Ramgir and S. Bhansali, 2008 a. Metal-decorated silica nanowires: An active surfaceenhanced Raman substrate for cancer biomarker detection. J. Phys. Chem. C, 112: 1729-1734. DOI: 10.1021/jp077698o 
Sekhar, P.K., N.S. Ramgir, R.K. Joshi and S. Bhansali, 2008b. Selective growth of silica nanowires using an $\mathrm{Au}$ catalyst for optical recognition of interleukin-10. Nanotechnology, 19: 245502. DOI: 10.1088/09574484/19/24/245502

Sinha, N. and J.T.W. Yeow, 2005. Carbon nanotubes for biomedical applications. IEEE Trans. Nanobiosci., 4: 180-195. DOI: 10.1109/tnb.2005.850478

Sodek, J., B. Ganss and M.D. McKee, 2000. Osteopontin. Crit. Rev. Oral Biol. Med., 11: 279303. DOI: $10.1177 / 10454411000110030101$

Takahashi, H. and M. Shibuya, 2005. The vascular endothelial growth factor (VEGF)/VEGF receptor system and its role under physiological and pathological conditions. Clin. Sci., 109: 227-241. DOI: $10.1042 / \mathrm{CS} 20040370$

Tang, L., C. Dong and J. Ren, 2010. Highly sensitive homogenous immunoassay of cancer biomarker using silver nanoparticles enhanced fluorescence correlation spectroscopy. Talanta, 81: 1560-1567. DOI: $10.1016 /$ j.talanta.2010.03.002

Teker, K., 2008. Bioconjugated carbon nanotubes for targeting cancer biomarkers. Mater. Sci. Eng. B, 153: 83-87. DOI: 10.1016/j.mseb.2008.10.026

Thompson, I.M., D.K. Pauler, P.J. Goodman, C.M. Tangen and M.S. Lucia et al., 2004. Prevalence of prostate cancer among men with a prostate-specific antigen level $<4.0 \mathrm{ng}$ per milliliter. New Engl. J. Med., 350: 2239-2246. DOI: $10.1056 /$ nejmoa031918

Tot, T., 2002. Cytokeratins 20 and 7 as biomarkers: Usefulness in discriminating primary from metastatic adenocarcinoma. Eur. J. Cancer, 38: 758763. DOI: 10.1016/S0959-8049(02)00008-4

Truong, P.L., B.W. Kim and S.J. Sim, 2012. Rational aspect ratio and suitable antibody coverage of gold nanorod for ultra-sensitive detection of a cancer biomarker. Lab Chip, 12: 1102-1109. DOI: $10.1039 / \mathrm{c} 21 \mathrm{lc} 20588 \mathrm{~b}$

Uludag, Y. and I.E. Tothill, 2010. Development of a sensitive detection method of cancer biomarkers in human serum (75\%) using a quartz crystal microbalance sensor and nanoparticles amplification system. Talanta, 82: 277-282. DOI: 10.1016/j.talanta.2010.04.034

Uludag, Y. and I.E. Tothill, 2012. Cancer biomarker detection in serum samples using surface plasmon resonance and quartz crystal microbalance sensors with nanoparticle signal amplification. Anal. Chem., 84: 5898-5904. DOI: 10.1021/ac300278p
Vinogradov, S. and X. Wei, 2012. Cancer stem cells and drug resistance: The potential of nanomedicine. Nanomedicine, 7: 597-615. DOI: 10.2217/nnm.12.22

Wan, Y., W.P. Deng, Y. Su, X.H. Zhu and C. Peng et al., 2011. Carbon nanotube-based ultrasensitive multiplexing electrochemical immunosensor for cancer biomarkers. Biosens. Bioelectron., 30: 93-99. DOI: $10.1016 /$ j.bios.2011.08.033

Wang, H.N. and T. Vo-Dinh, 2009. Multiplex detection of breast cancer biomarkers using plasmonic molecular sentinel nanoprobes. Nanotechnology, 20: 065101. DOI: 10.1088/0957-4484/20/6/065101

Wang, K., V. Bodempudi, Z. Liu, E. Borrego-Diaz and F. Yamoutpoor et al., 2012. Inhibition of mesothelin as a novel strategy for targeting cancer cells. PLoS ONE, 7: e33214. DOI: 10.1371/journal.pone.0033214

Wei, Q., Y.F. Zhao, C.X. Xu, D. Wu and Y.Y. Cai et al., 2011. Nanoporous gold film based immunosensor for label-free detection of cancer biomarker. Biosens. Bioelectron., 26: 3714-3718. DOI: 10.1016/j.bios.2011.02.024

Weiss, P.S., 2010. Nanoscience and nanotechnology: Present and future. ACS Nano, 4: 1771-1772. DOI: $10.1021 / \mathrm{nn} 100710 \mathrm{n}$

Xiao, Y. and X. Gao, 2010. Use of IgY antibodies and semiconductor nanocrystal detection in cancer biomarker quantitation. Biomarkers Med., 4: 227 239. DOI: $10.2217 / \mathrm{bmm} .10 .7$

$\mathrm{Xu}, \mathrm{Y} ., \mathrm{K} . \mathrm{He}$ and A. Goldkorn, 2011. Telomerase targeted therapy in cancer and cancer stem cells. Clin. Adv. Hematol. Oncol., 9: 442-455. PMID: 21841744

Yu, X., B. Munge, V. Patel, G. Jensen and A. Bhirde et al., 2006. Carbon nanotube amplification strategies for highly sensitive immunodetection of cancer biomarkers. J. Am. Chem. Soc., 128: 11199-11205. DOI: $10.1021 / \mathrm{ja} 062117 \mathrm{e}$

Zhang, G.J., J.H. Chua, R.E. Chee, A. Agarwal and S.M. Wong, 2009. Label-free direct detection of miRNAs with silicon nanowire biosensors. Biosens. Bioelectron., 24: 2504-2508. DOI: 10.1016/j.bios.2008.12.035

Zhang, L., P. Chen and L. Lin, 2013. Preparation of a luminescent zinc(II) coordination polymer and its encapsulation in the nanoporous channels. Inorg. Chem. Commun., 27: 156-158. DOI: 10.1016/j.inoche.2012.11.002 
Zhang, T., S. Mubeen, N.V. Myung and M.A. Deshusses, 2008. Recent progress in carbon nanotube-based gas sensors. Nanotechnology, 19: 332001. DOI: 10.1088/0957-4484/19/33/332001

Zhang, X.A., Y.Q. Teng, Y. Fu, S.P. Zhang and T. Wang et al., 2011. Lectin-based electrochemical biosensor constructed by functionalized carbon nanotubes for the competitive assay of glycan expression on living cancer cells. Chem. Sci., 2: 2353-2360. DOI: 10.1039/c1sc00562f

Zhao, P., M. Dai, W.Q. Chen and N. Li, 2010. Cancer trends in China. Jpn. J. Clin. Oncol., 40: 281-285. DOI: $10.1093 /$ jjco/hyp 187
Zheng, G.F., F. Patolsky, Y. Cui, W.U. Wang and C.M. Lieber, 2005. Multiplexed electrical detection of cancer markers with nanowire sensor arrays. Nat. Biotechnol., 23: 1294-1301. DOI: 10.1038/nbt1138

Zhou, W.H., C.L. Zhu, C.H. Lu, X.C. Guo and F.R. Chen et al., 2009. Amplified detection of protein cancer biomarkers using DNAzyme functionalized nanoprobes. Chem. Commun., 45: 6845-6847. DOI: 10.1039/b916217h

Zilberman, Y., U. Tisch, G. Shuster, W. Pisula and X. Feng et al., 2010. Carbon nanotube/hexa-perihexabenzocoronene bilayers for discrimination between nonpolar volatile organic compounds of cancer and humid atmospheres. Adv. Mater., 22: 4317-4320. DOI: 10.1002/adma.201001275 